\title{
Cold Atmospheric Pressure Plasma Jet for the Improvement of Wettability of Polypropylene
}

\author{
Hom Bahadur Baniya $\mathbb{D}^{1,2}$ Rajesh Prakash Guragain $\mathbb{D D}^{1}$ Binod Baniya $\mathbb{D}^{1}{ }^{3}$ \\ and Deepak Prasad Subedi ${ }^{1}{ }^{1}$ \\ ${ }^{1}$ Department of Physics, School of Science, Kathmandu University, Dhulikhel, Nepal \\ ${ }^{2}$ Department of Physics, Tri-Chandra Multiple Campus, Tribhuvan University, Kathmandu, Nepal \\ ${ }^{3}$ Department of Environmental Science, Patan Multiple Campus, Tribhuvan University, Kathmandu, Nepal
}

Correspondence should be addressed to Hom Bahadur Baniya; hom.baniya@student.ku.edu.np and Rajesh Prakash Guragain; rayessprakash@gmail.com

Received 10 March 2020; Accepted 28 May 2020; Published 20 June 2020

Academic Editor: Huining Xiao

Copyright (c) 2020 Hom Bahadur Baniya et al. This is an open access article distributed under the Creative Commons Attribution License, which permits unrestricted use, distribution, and reproduction in any medium, provided the original work is properly cited.

This paper reports the generation of cold plasma jet working under atmospheric pressure condition, for surface treatment of polymeric films. The discharge has been characterized by electrical and optical methods. The electrical property of the discharge has been studied by taking current-voltage wave forms using voltage and current probes. The production of argon plasma jet is done in atmospheric conditions which are relatively much cheaper, convenient, and safer to use. The atmospheric pressure plasma jet sustained in pure argon has been used to improve wettability of polypropylene (PP). Cold atmospheric pressure plasma jet (CAPPJ) has been generated by a high-voltage power supply $(5.5 \mathrm{kV}, 0-20 \mathrm{kV})$ at an operating frequency of $20 \mathrm{kHz}$. The surface properties of the controls and plasma-treated PP samples were characterized by contact angle measurement, surface free energy measurement, scanning electron microscopy, and the Fourier transform-infrared spectroscopy analysis.

\section{Introduction}

In the last two decades, plasma treatment of wood plastic composite (WPC) has been gaining popularity as a surface modification technique. WPC is a material composed of polymer plastic and wood fiber as a raw material. Polymer plastic has high strength for many structural designs, highly used in decoration and wood plastic building due to excellent processing anticorrosion and water resistance [1]. Plastics are both natural and synthetic; specially, synthesized plastic contains ester groups, and benzene ring can interact with polymer chain which brings compatibility then increases the intermolecular spacing. The cold plasma treatment effect has been used for improving the wettability on the polymer surface [2-4]. An effort has been made to electrically characterize atmospheric pressure argon plasma jet with respect to applied voltage and frequency to understand the dynamic behavior of discharge. The plasma jet is generated with a capacitive coupled dielectric barrier discharge and a working gas of argon flowing out into the environmental air [4-6]. The produced cold plasma jet has a variety of applications in biological sectors which is harmless for human because of its low voltage and can be used clinically $[7,8]$. In order to characterize the plasma jet, its electron temperature and its composition have been determined by means of optical emission spectroscopy $[9,10]$. Polypropylene is a synthesized plastic which is innately hydrophobic, is low-surface energy, and thus does not adhere well to other materials; hence, it is necessary to modify their surface properties to enhance the wettability of polymeric materials [11-13]. The application of plasma jet to the treatment of polymeric materials has become increasingly important and is used to increase the adhesion strengths from control to plasmatreated samples by incorporation of oxygen-containing polar functional groups on the surface of polymers [14-16]. Surface modification by cold plasma is responsible for 

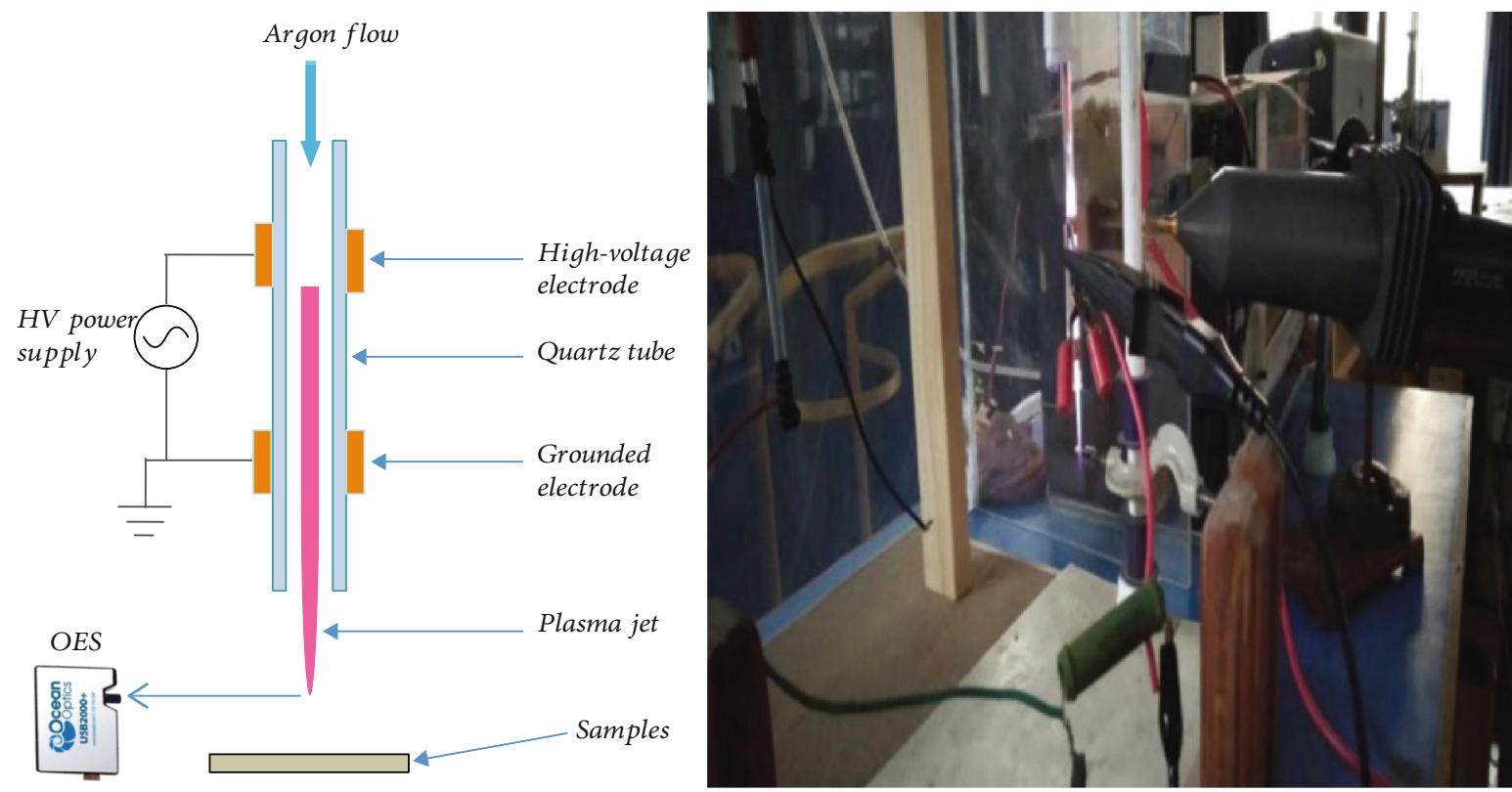

Figure 1: Schematic diagram of the experimental setup and image of the discharge.

modifying the surface properties without changing the bulk properties of the polymers by incorporating particular polar functional groups such as carbonyl $(-\mathrm{C}=\mathrm{O})$, carboxyl $(-\mathrm{COOH})$, and hydroxyl $(-\mathrm{OH})$ on the polypropylene surface [17-21].

\section{Materials}

Figure 1 shows the schematic diagram of the experimental setup and image of the discharge. The experimental setup consists of electrode system made of copper foil of thickness $0.15 \mathrm{~cm}$ wrapped around a quartz tube with an outer diameter of $0.5 \mathrm{~cm}$ and an inner diameter of $0.4 \mathrm{~cm}$. A high-voltage power supply $(0-20 \mathrm{kV})$ was applied across the copper electrodes. The interelectrode distance is fixed at $8 \mathrm{~cm}$, and the distance between the tip of the nozzle and grounded electrode is $0.3 \mathrm{~cm}$. Argon was used as the main working gas in the experiment. The flow rate for argon gas was $3 \mathrm{~L} / \mathrm{min}$, and the voltage and frequency were maintained at $5.5 \mathrm{kV}$ and $20 \mathrm{kHz}$ (operating frequency), respectively. Electrical characterization of the discharge was done with the help of the TEKTRONIX TDS2002 oscilloscope by measuring the current and voltage waveform with current probe and voltage probe (PINTEX HVP-28HF), respectively. The attenuation ratio of the voltage probe was $1000: 1$. The current waveform was measured by placing a current probe across a shunt resistor of $10 \mathrm{k} \Omega$. The Rame-Hart goniometer (model 200) was used for the measurement of contact angle of the control and plasma-treated polypropylene films. The ATR-FTIR spectroscopy measurements on polymer foils were performed with a Perkin Elmer Spectrum 100 FTIR spectrometer fitted with the Universal Attenuated Total Reflectance (UATR) polarization accessory in the spectral range of $4000-500 \mathrm{~cm}^{-1}$ at a resolution of $4 \mathrm{~cm}^{-1}$ for 20 accumulations per analysis. The LEO (500)/Zeiss field-emission scanning electron microscope (SEM) was used to check the surface roughness of polymeric materials.

\section{Methods}

The power balance method was used for the estimation of electron density. Similarly, optical characterization of the discharge was done using the Stark broadening method and the Boltzmann plot method with the help of an optical emission spectrometer (USB 2000+, Ocean Optics). The samples of polymeric films (PP) were treated by plasma jet by placing it vertically $2.5 \mathrm{~cm}$ below from the tip of the nozzle. Samples of PP with dimension $60 \mathrm{~mm} \times 20 \mathrm{~mm} \times 0.05 \mathrm{~mm}$ were used. The samples were provided by Goodfellow, UK. Before treatment, removal of organic contaminants from the surface of the specimens was done by rinsing in isopropyl alcohol for $10 \mathrm{~min}$. The samples were then ultrasonically cleaned in distilled water for 15 minutes and after that dried at room temperature in a clean environment. The contact angle measurements were done at five different locations on the same sample, and the average value of the contact angle obtained was used for the surface energy calculations.

\section{Results and Discussion}

4.1. Temperature of Atmospheric Pressure Plasma Jet. The atmospheric pressure plasma discharge approximately matches with the surrounding atmosphere. This plasma is also called normal plasma. The plasma jet was designed with locally available materials to make treatment continuous and cost effective. Temperature of plasma jet was experimentally found to be about $27^{\circ} \mathrm{C}$ at $5.5 \mathrm{kV}$. So, it is called cold atmospheric pressure plasma jet and is widely used for the surface modification of polypropylene. 


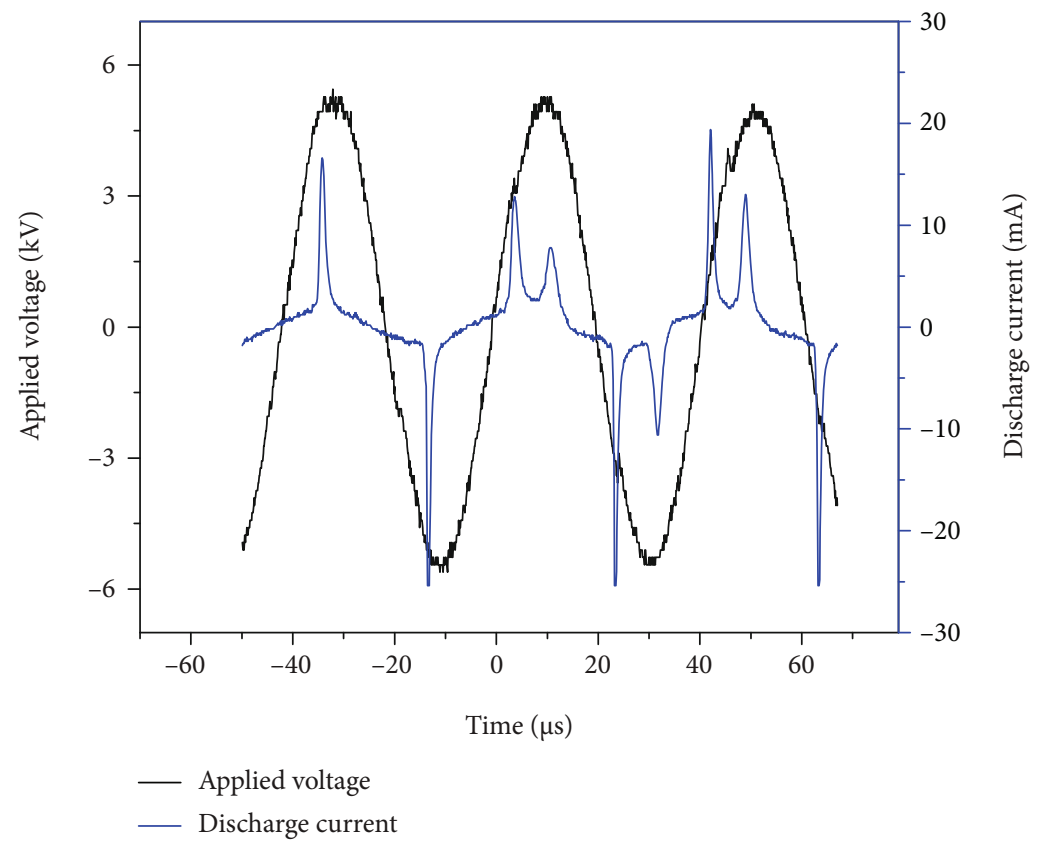

Figure 2: Current-voltage graph at gas flow rate $Q=3 \mathrm{~L} / \mathrm{min}$ at an applied voltage of $5.5 \mathrm{kV}$.

4.2. Electrical Characterization of APPJ. The total power consumed by a plasma jet can be written as $P_{a v}=2 \mathrm{An}_{\mathrm{e}} v_{\mathrm{b}}$ $E_{\text {lost }}$, where $2 \mathrm{An}_{\mathrm{e}} v_{\mathrm{b}} E_{\text {lost }}$ represents the total power of the discharge over the area $2 A$ of the two electrodes and $v_{\mathrm{b}}$ being the Bohm velocity. Therefore, the expression for electron density is

$$
n_{\mathrm{e}}=\frac{P_{a v}}{2 A v_{\mathrm{b}} E_{\mathrm{lost}}} .
$$

This equation can be used to determine the electron density in the glow mode of the discharge [22].

Figure 2 shows the current and voltage waveforms of APPJ generated in argon with an electrode gap of $8 \mathrm{~cm}$ and an applied voltage of $5.5 \mathrm{kV}$ at an atmospheric pressure condition. Using the values of applied voltage and average discharge current, the electron density is determined using equation (1). Putting the value of the Bohm velocity $v_{\mathrm{b}}=$ $2 \times 10^{3} \mathrm{~m} / \mathrm{s}$, energy lost $80 \times 10^{-19}$ Joule, electrode area $4.096 \times 10^{-5} \mathrm{~m}^{2}$, applied voltage $5.5 \mathrm{kV}$, and discharge current about $25 \mathrm{~mA}$, the electron density was found to be $n_{\mathrm{e}}=$ $7.6 \times 10^{16} \mathrm{~cm}^{-3}$. The power consumed per cycle was about 137.5 Watt.

\subsection{Optical Characterization of APPJ}

4.3.1. Stark Broadening Method. The emission spectra of the discharge were also used to measure electron density, using the Stark broadening method [23, 24].

Figure 3 shows the optical spectrum (left) and its Lorentzian fit (right) of the data for the line. In this method, the prominent argon line at $696.54 \mathrm{~nm}$ was chosen for the estimation of electron density. The full width at half maximum
(FWHM) of the Stark broadening $\Delta \lambda_{\text {Stark }}$ is related to the electron density represented by equation (2).

$$
\Delta \lambda_{\text {Stark }}=2 \times 10^{-11} n_{\mathrm{e}}^{2 / 3} .
$$

From the FWHM method, the calculated value of $\Delta \lambda_{\text {Stark }}$ is obtained $(1.65 \mathrm{~nm})$ and putting this value in equation (2), the corresponding electron density $\left(n_{\mathrm{e}}\right)$ was found to be about $2.27 \times 10^{16} \mathrm{~cm}^{-3}$.

4.3.2. The Boltzmann Plot Method. For the determination of electron temperature, the discharge was diagnosed by using the Boltzmann plot method. In this method, seven suitable lines of Ar I were taken from the spectral lines of argon plasma discharge. The working formula used to calculate the electron temperature is expressed in equation (3) as follows [25].

$$
\ln \left[\frac{\lambda I}{h c A_{j i} g_{j}}\right]=-\frac{E_{j}}{k T_{\mathrm{e}}}+C
$$

A plot of the above equation with $E_{j}$ on the horizontal axis and $\ln \left(\lambda I / h c A_{j i} g_{j}\right)$ on the vertical axis was made which resulted in a straight line, and the electron temperature $\left(T_{\mathrm{e}}\right)$ was obtained from the slope of the straight line which is shown in Figure 4.

From Figure 4, the electron temperature was found to be of the order of $1.03 \mathrm{eV}$, which corresponds to an electron temperature of about $11845^{\circ}$ Kelvin.

\subsection{Surface Modification of Polypropylene}

4.4.1. Contact Angle and Surface Energy Measurements. In a homogeneous surface, the water contact angle and surface 


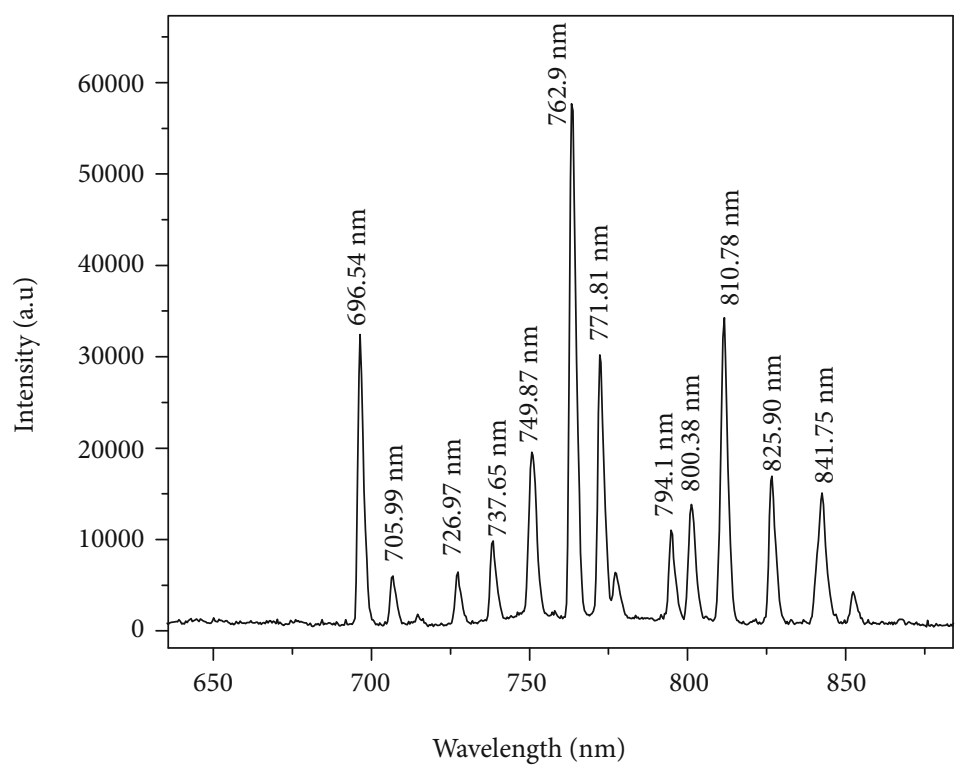

(a)

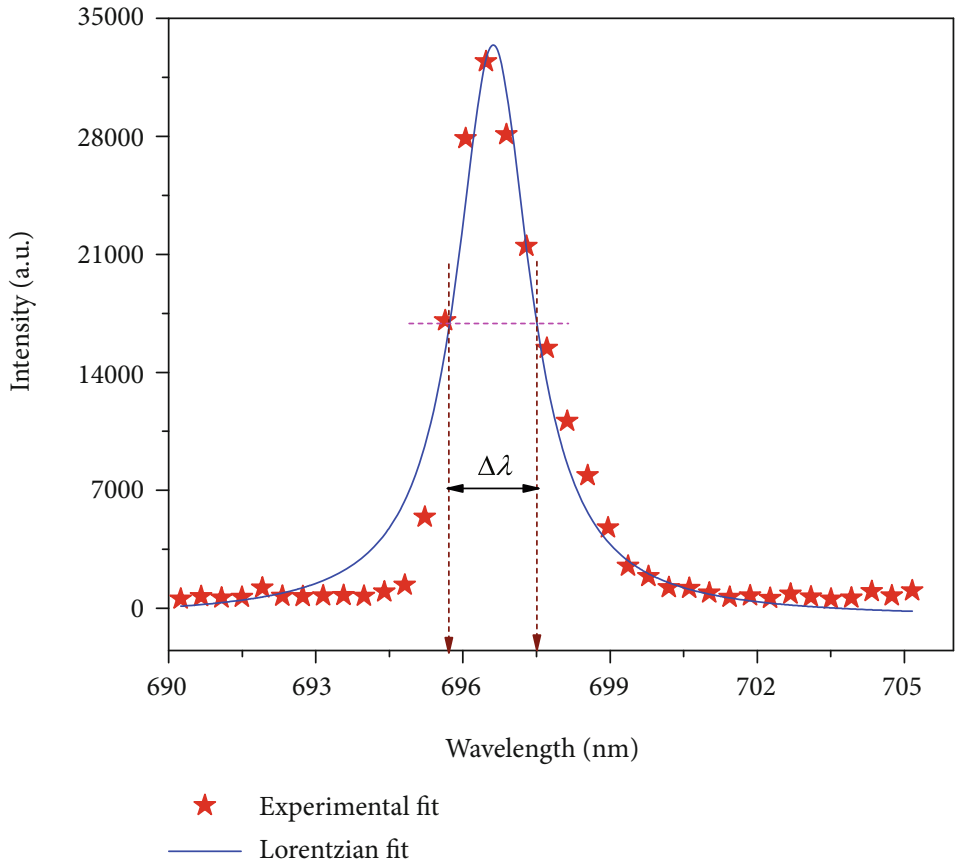

(b)

Figure 3: Spectrum of the discharge at $5.5 \mathrm{kV}$ with a frequency of $20 \mathrm{kHz}$ in $\operatorname{argon}$ (flow rate $=3 \mathrm{~L} / \mathrm{min}$ ).

energy were determined according to the Young equation and the Owens-Wendt methods, respectively $[26,27]$.

$$
\cos \theta=\frac{\gamma_{\mathrm{sv}}-\gamma_{\mathrm{sl}}}{\gamma_{\mathrm{lv}}}
$$

Here, $\gamma_{\mathrm{sv}}$ is the surface free energy of the solid substrate, $\gamma_{\mathrm{sl}}$ is the interfacial free energy between the solid and the liquid, and $\gamma_{\mathrm{lv}}$ is the surface tension of the liquid.
In the case of two liquids $i$ and $j$,

$$
\begin{aligned}
& \gamma_{l i}\left(1+\cos \theta_{i}\right)=2\left(\gamma_{l i}^{d} \gamma_{s}^{d}\right)^{1 / 2}+2\left(\gamma_{l i}^{p} \gamma_{s}^{p}\right)^{1 / 2}, \\
& \gamma_{l j}\left(1+\cos \theta_{j}\right)=2\left(\gamma_{l j}^{d} \gamma_{s}^{d}\right)^{1 / 2}+2\left(\gamma_{l j}^{p} \gamma_{s}^{p}\right)^{1 / 2} .
\end{aligned}
$$

By using the values of the surface tension and its polar and dispersion components of the test liquids, components of the surface energy of the solid, $\gamma_{s}^{p}$ and $\gamma_{s}^{d}$ can be 


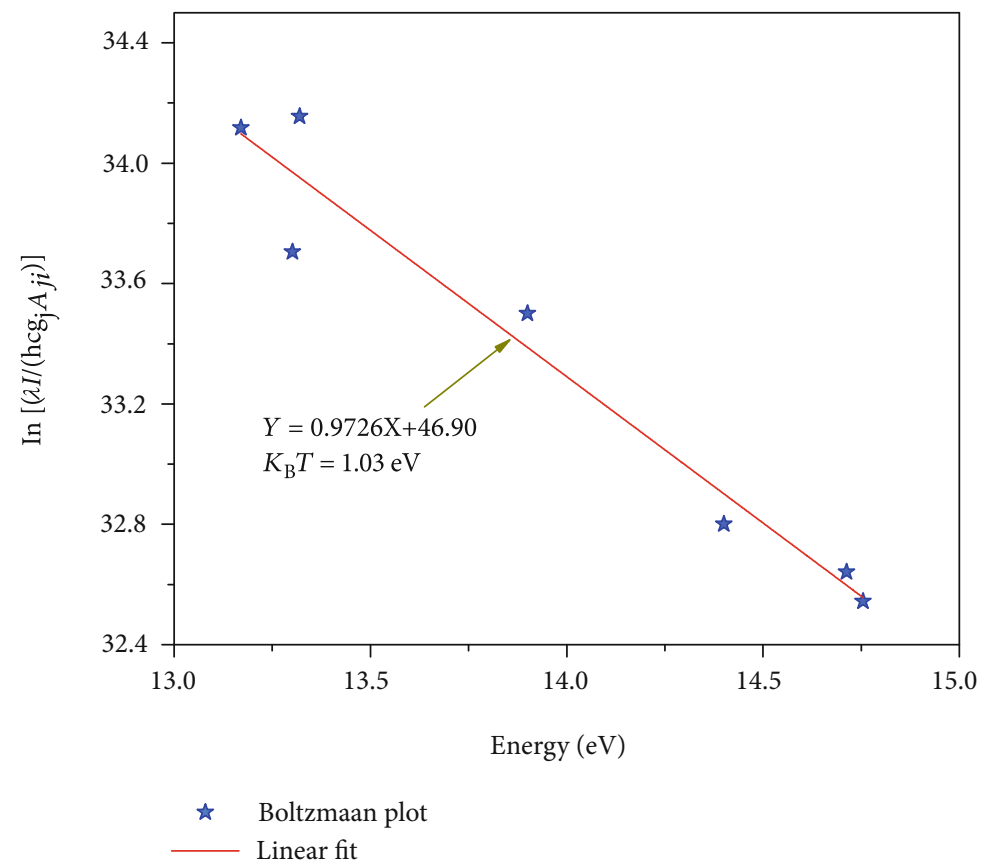

FIgURE 4: The Boltzmann plot method for the determination of electron temperature.

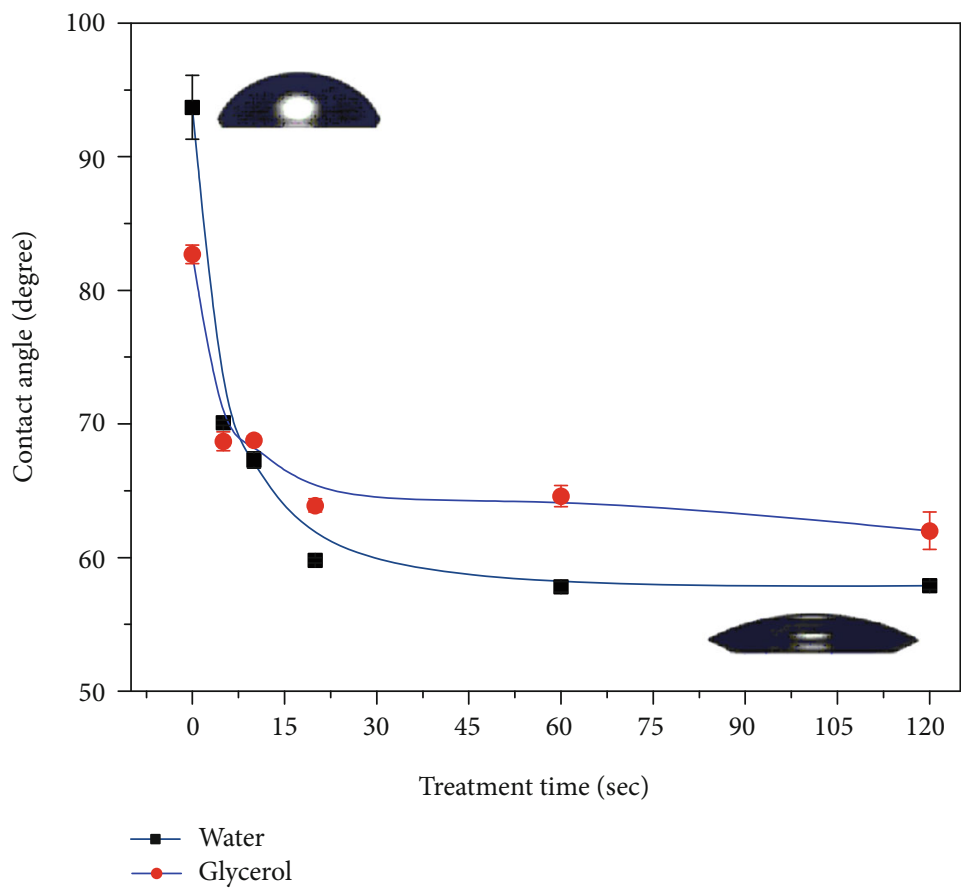

Figure 5: Variation of the contact angle of polypropylene with treatment time.

determined from equations (5) and (6). The addition of these two quantities represents the total surface energy of the solid [28].

Figure 5 shows the variation of contact angle of PP samples with treatment time. The effect of treatment time on the wettability was investigated, using a contact angle goniometer (model 200) by using two test liquid models (water and glycerol) on the surface of the polymers. Results showed that a vast decrease in the contact angle takes place with the treatment time up to 120 seconds. At first, the contact angles on the control sample for water and glycerol were $94.5^{\circ}$ and $84^{\circ}$, but after plasma jet treatment, the contact angles were reduced to $57^{\circ}$ and $65^{\circ}$, respectively, and became constant after a treatment time of 30 seconds. The reduction in contact angle might be due to the increase in roughness on the surface of PP $[14,19,29,30]$. 


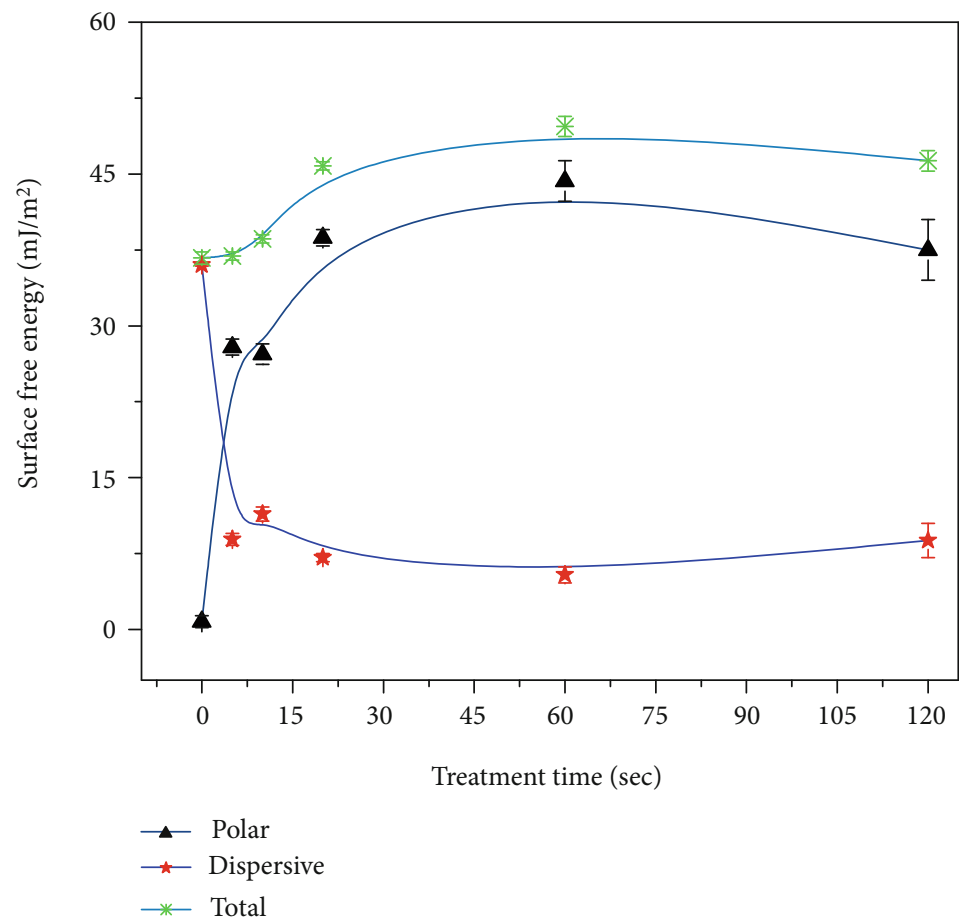

FIGURE 6: Variation of surface free energy of polypropylene with treatment time.

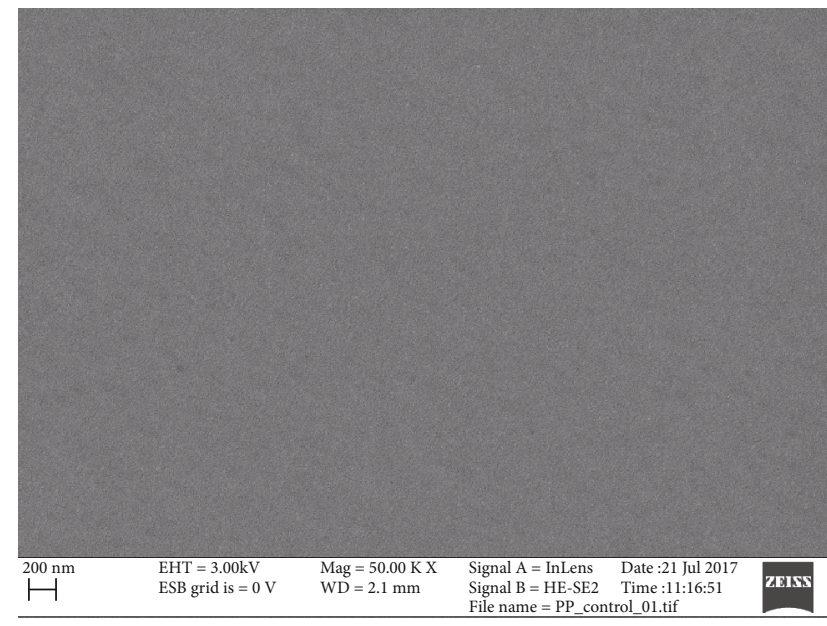

(a)

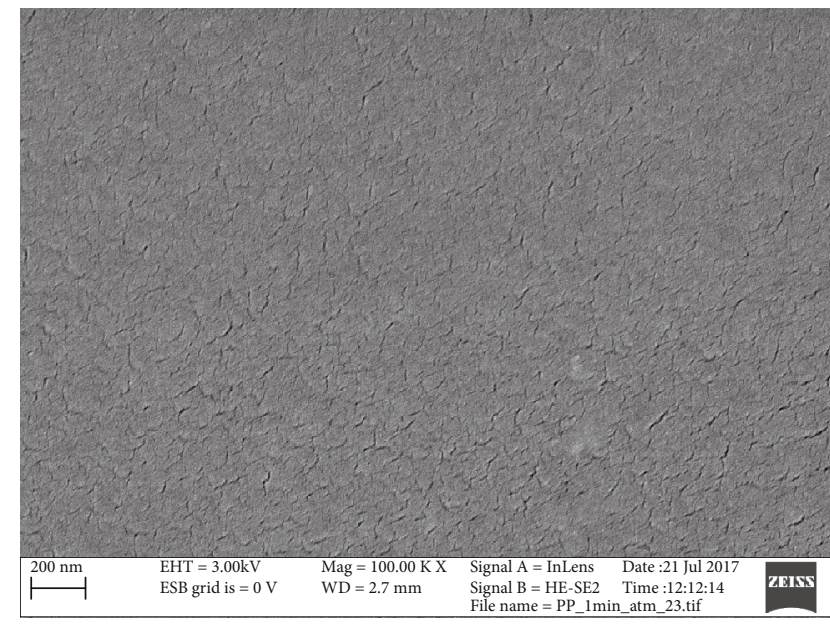

(b)

FIGURE 7: SEM images of untreated (a) and plasma-treated (b) samples of PP at 60 seconds.

Figure 6 shows the variation of surface energy and its polar and dispersive components of PP samples with a treatment time of 120 seconds. The total surface energy increases from $37 \mathrm{~mJ} / \mathrm{m}^{2}$ to $48 \mathrm{~mJ} / \mathrm{m}^{2}$ in 35 seconds. A similar trend is also observed for the polar component, and it is mainly due to the incorporation of the polar species such as carbonyl $(\mathrm{C}=\mathrm{O})$, hydroxyl $(-\mathrm{OH})$, and carboxyl $(-\mathrm{COOH})$ groups on the polymer surface after treatment. The dispersion component does not have any contribution to increase the hydrophilicity on the polypropylene surface $[13,14,20,31]$.
4.4.2. SEM Images of the Untreated and Plasma-Treated PP. Figure 7 shows the SEM morphology of the untreated and plasma-treated polymer surface of PP at 60 seconds. The gradual increase in the particle grain size with the image scan area can be realized. The change in surface roughness of the sample after treatment was analyzed by scanning electron microscopy (SEM). SEM images of untreated and argon plasma jet-treated sample indicated that the plasma treatment produces a significant increase roughness on the surface of PP [30]. 


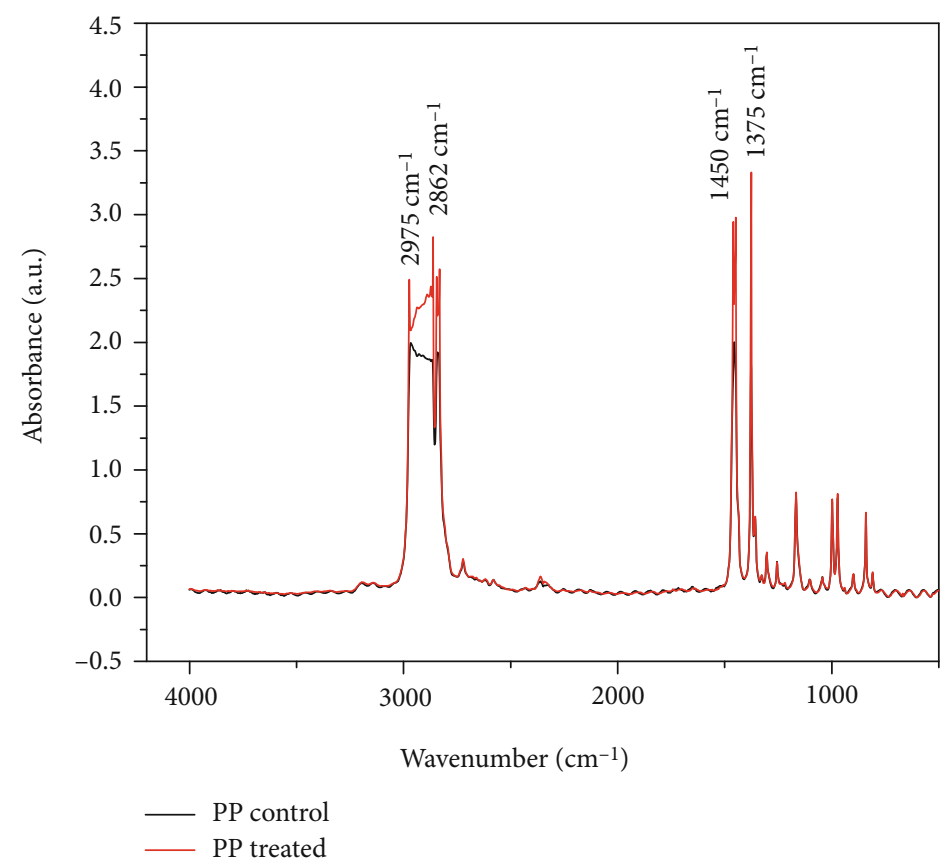

FIGURE 8: FTIR spectra of untreated and plasma-treated sample of polypropylene.

4.4.3. FTIR Analysis. Figure 8 shows the FTIR spectra of the untreated and cold plasma jet-treated samples of polypropylene. There is change in intensity of absorption peaks due to incorporation of oxygen-containing polar functional groups on the surface of polymer after plasma jet treatment. FTIR spectra shows the presence of carbonyl peaks $(C=O)$ which represents surface oxidation. Previous studies have also shown a similar result that to oxidize can be confirmed due to presence of carbonyl peaks and stretching of $\mathrm{C}-\mathrm{H}$ bonds at wavelengths $1450 \mathrm{~cm}^{-1}$ and $1375 \mathrm{~cm}^{-1}$, respectively. The stretching of $\mathrm{C}-\mathrm{H}$ bonds and aromatic rings were obtained at wavelengths 2862 to $2975 \mathrm{~cm}^{-1}$, respectively [30-35].

\section{Conclusions}

The cost-effective system of generating plasma jet at an atmospheric pressure with the potential application in material processing has been developed. The temperature of the plasma jet was measured to be about $27^{\circ} \mathrm{C}$ at $5.5 \mathrm{kV}$. So, this discharge is termed as cold plasma and is widely used in heatsensitive material processing. Atmospheric pressure plasma jet has been characterized by optical and electrical methods. Electron density $\left(n_{\mathrm{e}}\right)$ and electron temperature $\left(T_{\mathrm{e}}\right)$ were found to be of the order of $10^{16} \mathrm{~cm}^{-3}$ using the Stark broadening and power balance methods and $1.03 \mathrm{eV}$ using the Boltzmann plot method. Cold plasma jet treatment of polypropylene effectively improves hydrophilicity. The contact angle of the polymer after plasma jet treatment was found to decrease whereas the corresponding surface energy was found to increase. It is due to the incorporation of polar functional groups on the PP surface after treatment. SEM images of the untreated and plasma jet-treated sample confirmed that the cold plasma treatment produces a significant improvement in the roughness of the surface of a polypro- pylene film. The FTIR analysis concludes that there is incorporation of oxygen-containing polar functional groups such as carbonyl $(\mathrm{C}=0)$ peaks and stretching of $\mathrm{C}-\mathrm{H}$ bonds on the surface of polypropylene which indicates the improvement of the wettability on the PP surface.

\section{Data Availability}

The data (figures) that support the findings of this study are available upon request from the corresponding author.

\section{Conflicts of Interest}

The authors declare that there is no conflict of interest regarding the publication of this research article.

\section{Acknowledgments}

The corresponding author was supported by the Nepal Academy of Science and Technology (NAST), Nepal, by providing a Ph.D. fellowship through Grant No.: 11/073/074. The authors would like to acknowledge Tri-Chandra Multiple Campus, Tribhuvan University, Institute of Science and Technology (IOST), Nepal for their invaluable help and support. The authors would like to thank Prof. Andrzej Huczko from the University of Warsaw, Poland, for the SEM analysis of the polymer samples.

\section{References}

[1] X. Yang, X. Tang, L. Ma, and Y. Sun, "Sound insulation performance of structural wood wall integrated with wood plastic composite," Journal of Bioresources and Bioproducts, vol. 4, no. 2, pp. 111-118, 2019. 
[2] G. Feng, Y. Ma, M. Zhang, P. Jia, C. Liu, and Y. Zhou, "Synthesis of bio-base plasticizer using waste cooking oil and its performance testing in soft poly(vinyl chloride) films," Journal of Bioresources and Bioproducts, vol. 4, no. 2, pp. 99110, 2019.

[3] K. B. Sim, D. Baek, J. H. Shin et al., "Enhanced surface properties of carbon fiber reinforced plastic by epoxy modified primer with plasma for automotive applications," Polymers, vol. 12, no. 3, p. 556, 2020.

[4] R. P. Guragain, S. Gautam, D. P. Subedi, and R. Shrestha, "Effect of plasma treatment on the surface of polyethylene terephthalate with $50 \mathrm{~Hz}$ dielectric barrier discharge at near atmospheric pressure," International Journal of Recent Research and Review, vol. 9, no. 4, pp. 34-37, 2016.

[5] A. V. Deynse, R. Morent, and N. D. Geyter, "Surface modification of polymers using atmospheric pressure cold plasma technology," in Polymer Science: Research Advances, Practical Applications and Educational Aspects, A. Méndez-Vilas and A. Solano, Eds., pp. 506-516, Formatex Research Center, 2016.

[6] C. Oehr, "Plasma surface modification of polymers for biomedical use," Nuclear Instruments and Methods in Physics Research Section B: Beam Interactions with Materials and Atoms, vol. 208, pp. 40-47, 2003.

[7] A. K. Shrestha, R. Shrestha, H. B. Baniya, R. B. Tyata, D. P. Subedi, and C. S. Wong, "Influence of discharge voltage and pressure on the plasma parameters in a low-pressure DC glow discharge," International Journal of Recent Research and Review, vol. 7, no. 2, pp. 9-15, 2014.

[8] H. Ulrich, Introduction to Industrial Polymers, Hanser Publishers, New York, 2nd edition, 1993.

[9] E. F. Castro Vidaurre, C. A. Achete, F. Gallo, D. Garcia, R. Simão, and A. C. Habert, "Surface modification of polymeric materials by plasma treatment," Materials Research, vol. 5, no. 1, pp. 37-41, 2002.

[10] H. S. Park, S. J. Kim, H. M. Joh, T. H. Chung, S. H. Bae, and S. H. Leem, "Optical and electrical characterization of an atmospheric pressure micro plasma jet with a capillary electrode," Physics of Plasmas, vol. 17, no. 3, article 033502, 2010.

[11] B. L. Eppley, W. S. Pietrzak, and M. Blanton, "Platelet-rich plasma: a review of biology and applications in plastic surgery," Plastic and Reconstructive Surgery, vol. 118, no. 6, pp. 147E-159E, 2006.

[12] H. B. Baniya, S. Shrestha, and D. P. Subedi, "Effect of floating electrode on the length of the capacitively coupled atmospheric pressure plasma jet," International Journal of Engineering Research Online, vol. 4, pp. 163-167, 2016.

[13] S. Bhowmik, P. K. Ghosh, and S. Ray, "Surface modification of HDPE and PP by mechanical polishing and DC glow discharge and their adhesive joining to steel," Journal of Applied Polymer Science, vol. 80, no. 8, pp. 1140-1149, 2001.

[14] A. Sarani, A. Y. Nikiforov, N. de Geyter, R. Morent, and C. Leys, "Surface modification of polypropylene with an atmospheric pressure plasma jet sustained in argon and an argon/water vapour mixture," Applied Surface Science, vol. 257, no. 20, pp. 8737-8741, 2011.

[15] E. M. Liston, L. Martinu, and M. R. Wertheimer, "Plasma surface modification of polymers for improved adhesion: a critical review," Journal of Adhesion Science and Technology, vol. 7, no. 10, pp. 1091-1127, 1993.

[16] A. Mercado-Cabrera, B. Jaramillo-Sierra, R. López-Callejas et al., "Surface modification of polypropylene fiber for hydro- philicity enhancement aided by DBD plasma," Progress in Organic Coatings, vol. 76, no. 12, pp. 1858-1862, 2013.

[17] A. Wolkenhauer, G. Avramidis, E. Hauswald, H. Militz, and W. Viol, "Plasma treatment of wood-plastic composites to enhance their adhesion properties," Journal of Adhesion Science and Technology, vol. 22, no. 16, pp. 2025-2037, 2008.

[18] C. B. Mello, K. G. Kostov, M. Machida, L. R. O. de Oliveira Hein, and K. A. de Campos, "Surface modification of polycarbonate by Atmospheric-Pressure plasma Jets," IEEE Transactions on Plasma Science, vol. 40, no. 11, pp. 2800-2805, 2012.

[19] U. M. Joshi and D. P. Subedi, "Surface treatment of polypropylene (PP) film by $50 \mathrm{~Hz}$ dielectric barrier discharge produced in air and argon/air mixture at atmospheric pressure," AIP Conference Proceedings, vol. 1670, article 0020003, 2015.

[20] D. Shaw, A. West, J. Bredin, and E. Wagenaars, "Mechanisms behind surface modification of polypropylene film using an atmospheric-pressure plasma jet," Plasma Sources Science and Technology, vol. 25, no. 6, 2016.

[21] H. B. Baniya, R. Shrestha, A. Shrestha et al., "Surface modification of polycarbonate by atmospheric pressure argon/air plasma jet," Kathmandu University Journal of Science, Engineering and Technology, vol. 10, no. 2, pp. 13-16, 2014.

[22] N. Balcon, A. Aanesland, and R. Boswell, "Pulsed RF discharges, glow and filamentary mode at atmospheric pressure in argon," Plasma Sources Science and Technology, vol. 16, no. 2, pp. 217-225, 2007.

[23] A. Falahat, A. Ganjovi, M. Taraz, M. N. R. Ravari, and A. Shahedi, "Optical characteristics of a RF DBD plasma jet in various $\mathrm{Ar} / \mathrm{O}_{2}$ mixtures," Pramana, vol. 90, no. 2, 2018.

[24] H. B. Baniya, "Experimental study of atmospheric pressure plasma jet (APPJ) with floating electrode and its application for polymer surface modification. M. Phil., Thesis," Kathmandu University, Nepal, 2016.

[25] S. Das, D. P. Das, C. K. Sarangi, B. Bhoi, B. K. Mishra, and J. Ghosh, "Optical emission spectroscopy study of $\mathrm{Ar}-\mathrm{H}_{2}$ plasma at atmospheric pressure," IEEE Transactions on Plasma Science, vol. 46, no. 8, pp. 2909-2915, 2018.

[26] Y. Yuan and T. R. Lee, "Contact Angle and Wetting Properties," in Surface Science Techniques, G. Bracco and B. Holst, Eds., vol. 51 of Springer Series in Surface Sciences, , pp. 3-34, Springer, 2013.

[27] R. P. Guragain, S. Gautam, R. Shrestha, and D. P. Subedi, "Surface modification of polycarbonate by treatment with $50 \mathrm{~Hz}$ dielectric barrier discharge at near atmospheric pressure," International Journal of Science and Research, vol. 5, no. 12, pp. 1468-1470, 2016.

[28] H. B. Baniya, R. P. Guragain, B. Baniya, G. Qin, and D. P. Subedi, "Improvement of hydrophilicity of polyamide using atmospheric pressure plasma jet," Bibechana, vol. 17, pp. 133138, 2019.

[29] T. S. M. Mui, R. P. Mota, A. Quade, L. R. . O. Hein, and K. G. Kostov, "Uniform surface modification of polyethylene terephthalate (PET) by atmospheric pressure plasma jet with a horn-like nozzle," Surface and Coatings Technology, vol. 352, pp. 338-347, 2018.

[30] M. S. Kang, B. Chun, and S. S. Kim, "Surface modification of polypropylene membrane by low temperature plasma treatment," Journal of Applied Polymer Science, vol. 81, no. 6, pp. 1555-1566, 2001.

[31] H. B. Baniya, R. Shrestha, R. P. Guragain, M. B. Kshetri, B. P. Pandey, and D. P. Subedi, "Generation and characterization 
of an atmospheric pressure plasma jet (APPJ) and its application in the surface modification of polyethylene terephthalate," International Journal of Polymer Science, vol. 2020, Article ID 9247642, 7 pages, 2020.

[32] N. De Geyter, R. Morent, and C. Leys, "Surface characterization of plasma modified polyethylene by contact angle experiments and ATR-FTIR spectroscopy," Surface and Interface Analysis, vol. 40, no. 3-4, pp. 608-611, 2008.

[33] D. L. Pavia, G. M. Lampman, and G. S. Kriz, Introduction to Spectroscopy, Thomson Brooks/Cole, Saunders College Division, Third edition, 2001.

[34] C. Tang, B. Shi, W. Gao, F. Chen, and Y. Cai, "Strength and mechanical behavior of short polypropylene fiber reinforced and cement stabilized clayey soil," Geo-textiles and Geo-membranes, vol. 25, no. 3, pp. 194-202, 2007.

[35] R. Morent, N. De Geyter, C. Leys, L. Gengembre, and E. Payen, "Comparison between XPS- and FTIR-analysis of plasmatreated polypropylene film surfaces," Surface and Interface Analysis, vol. 40, no. 3-4, pp. 597-600, 2008. 